\title{
Fungal, Parasitological, and bacterial coinfection in a severely ill COVID-19 patient in Peru
}

Jeel Moya Salazar ${ }^{1}$, Sharon Sauñe ${ }^{2}$, Roxana Valer ${ }^{2}$, Richard Salazar-Hernandez ${ }^{3}$, Wilfredo Loza $^{2}$, Evelyn Suxe ${ }^{2}$, Karina Chicoma-Flores ${ }^{4}$, and Hans Contreras-Pulache ${ }^{4}$

${ }^{1}$ Hospital Nacional Docente Madre Nino San Bartolome

${ }^{2}$ Hospital Carlos Lanfranco La Hoz

${ }^{3}$ Hospital Nacional Guillermo Almenara

${ }^{4}$ Universidad Norbert Wiener

August 25, 2021

\begin{abstract}
COVID-19 patients are prone to co-infections during their hospitalization. These co-infections are challenging as they involve longer hospital stays, high costs, and higher mortality risk. Here we present a case of a patient with multi-infection by resistant parasites, fungi, and bacteria during his hospitalization in a Peruvian hospital
\end{abstract}

\section{Hosted file}

Text_2021_final_3.docx available at https://authorea.com/users/431747/articles/535235-fungalparasitological-and-bacterial-coinfection-in-a-severely-ill-covid-19-patient-in-peru

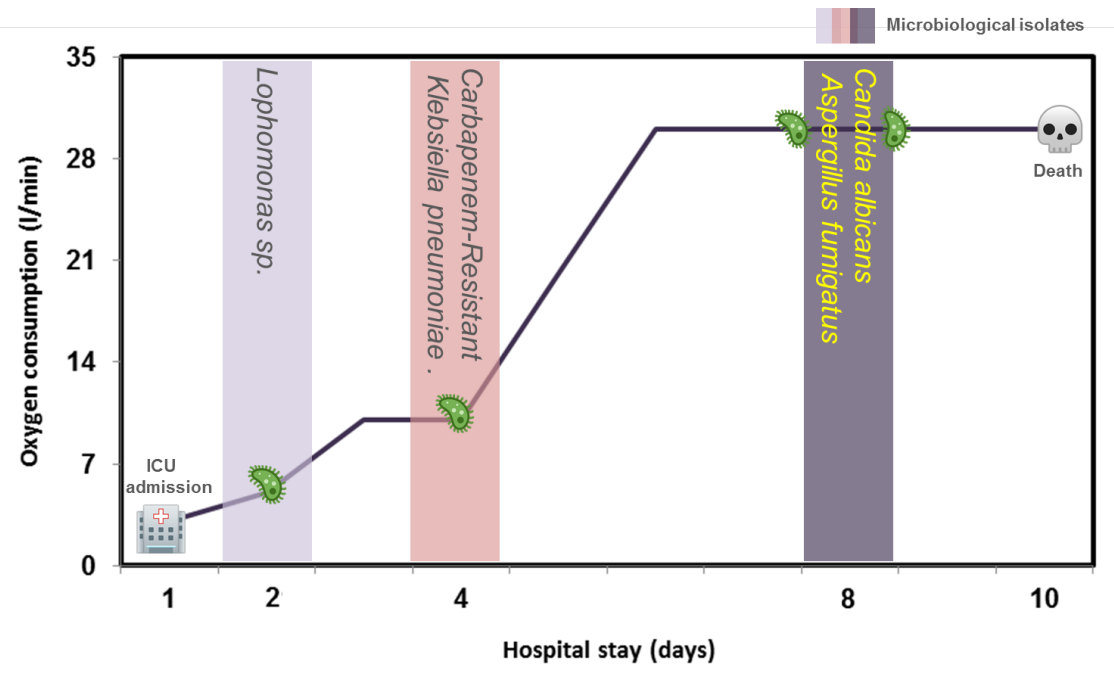



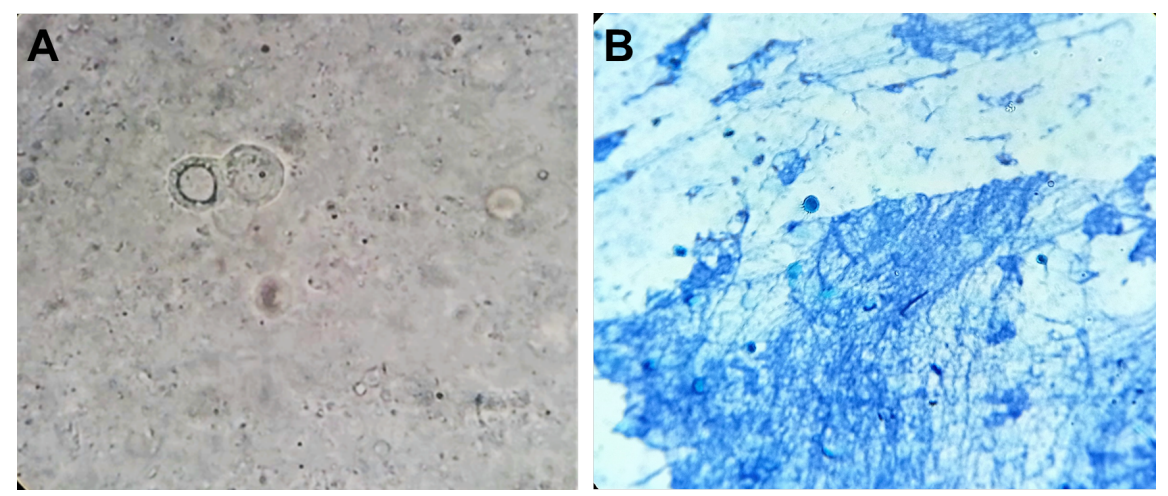